MICHIGAN RETIREMENT AND DISABILITY RESEARCH CENTER UNIVERSITY OF MICHIGAN

Promoting research on retirement, disability, and Social Security policy

\title{
Setting Expectations for Claimant Ability to Work: Investigating the Occupational Requirements and Functional Capacity of Workers with Early Onset Health Conditions
}

Andrew J. Houtenville and Deniz Ozabaci

MRDRC WP 2019-404

UM19-09 


\title{
Setting Expectations for Claimant Ability to Work: Investigating the Occupational Requirements and Functional Capacity of Workers with Early Onset Health Conditions
}

\author{
Andrew J. Houtenville \\ University of New Hampshire
}

\author{
Deniz Ozabaci \\ University of New Hampshire
}

\section{October 2019}

Michigan Retirement and Disability Research Center, University of Michigan, P.O. Box 1248. Ann Arbor, MI 48104, https://mrdrc.isr.umich.edul, (734) 615-0422

\section{Acknowledgements}

The research reported herein was performed pursuant to a grant from the U.S. Social Security Administration (SSA) funded as part of the Retirement Research Consortium through the University of Michigan Retirement Research Center Award RDR18000002. The opinions and conclusions expressed are solely those of the author(s) and do not represent the opinions or policy of SSA or any agency of the federal government. Neither the United States government nor any agency thereof, nor any of their employees, makes any warranty, express or implied, or assumes any legal liability or responsibility for the accuracy, completeness, or usefulness of the contents of this report. Reference herein to any specific commercial product, process or service by trade name, trademark, manufacturer, or otherwise does not necessarily constitute or imply endorsement, recommendation or favoring by the United States government or any agency thereof.

\section{Regents of the University of Michigan}

Jordan B. Acker; Huntington Woods; Michael J. Behm, Grand Blanc; Mark J. Bernstein, Ann Arbor; Paul W. Brown, Ann Arbor; Shauna Ryder Diggs, Grosse Pointe; Denise llitch, Bingham Farms; Ron Weiser, Ann Arbor; Katherine E. White, Ann Arbor; Mark S. Schlissel, ex officio 


\title{
Setting Expectations for Claimant Ability to Work: Investigating the Occupational Requirements and Functional Capacity of Workers with Early Onset Health Conditions
}

\begin{abstract}
When determining a claimant's eligibility for Social Security Disability Insurance (SSDI) benefits, the Social Security Administration (SSA) assesses whether his/her health condition (e.g., back/spine problems) sufficiently impairs his/her functional capacity (e.g., ability to lift/carry weight) so that the he/she is unable to meet the requirements (e.g., need to lift/carry 25 pounds) of his/her previous occupation and other possible occupations. Using data from the Survey of Income and Program Participation (SIPP) and Occupational Requirements Survey (ORS), we compare the occupational requirements of workers with and without a given health condition in order to understand what to expect from claimants with that health condition. Although sample sizes are limiting and ORS data collection is not yet complete, we find some evidence that workers' occupational requirements accommodate their health conditions. This evidence suggests that claimants with these health conditions may be able to fulfill the requirements in these occupations. We do find some evidence of the opposite causality: Workers may experience health conditions later in life from occupational requirements that may have caused their health conditions. This evidence is a caution against using data without onset information to inform claimant-ability expectations. Overall, this report provides evidence that national surveys with occupation, health, and function questions have the potential to inform revisions to the SSA disability determination process by providing information on people with health conditions who are working and meeting the requirements of a variety of occupations.
\end{abstract}

\section{Citation}

Houtenville, Andrew J., and Deniz Ozabaci. 2019. "Setting Expectations for Claimant Ability to Work: Investigating the Occupational Requirements and Functional Capacity of Workers with Early Onset Health Conditions." Ann Arbor, MI. University of Michigan Retirement and Disability Research Center (MRDRC) Working Paper; MRDRC WP 2019-404.

https://mrdrc.isr.umich.edu/publications/papers/pdf/wp404.pdf 


\section{Introduction}

When determining a claimant's eligibility of Social Security Disability Insurance (SSDI) benefits, the Social Security Administration (SSA) assesses, in part, if the claimant's health condition is sufficiently severe that the claimant is incapable of sustaining substantial gainful activity (SGA), defined in 2019 for the nonblind claimant as earning more than $\$ 1,220$ monthly. The severity of some health conditions means that the condition's presence is sufficient to impair the claimant's ability to work above SGA. The severity of other health conditions is less observable and certain, and thus, the claimant's work-related functional capacity is assessed in comparison to the occupational requirements of the claimant's occupation and other potential occupations in the U.S. economy, where other potential occupations are based on vocational factors such as age and the transferability of prior work experience. As a result, understanding the ability of people with health conditions to fulfill occupational requirements is crucial for knowing what to expect of claimants. However, there is little population-based information on ability of health-challenged people fulfill the occupational requirements.

Using nationally representative data from the Survey of Income and Program Participation (SIPP) SSA Supplement, we investigate the occupational requirements of current workers with health conditions. We pay particular attention to workers who experience the health condition early in life (prior to working) because some health conditions may result from fulfilling hazardous occupational requirements, and thus, estimates of the occupational requirements of these health conditions may be overstated. 
In doing so, we lay the foundation for future studies investigating the validity of the various elements of and potential changes to the SSA disability determination process—elements such as the Listing of Impairments, the Medical-Vocational Grid, the Work Disability-Functional Assessment Battery (WD-FAB), and the forthcoming Occupational Information System (OIS).

\section{Background and literature}

When determining a claimant's eligibility for a disability benefits, the Social Security Administration (SSA) assesses whether the claimant's ability to work might be limited by any medically determinable physical or mental impairment that can be expected to last for a continuous period of not less than 12 months (SEC. 223, 42 U.S.C. 423(d)(1)). To be eligible for benefits, the physical impairment, mental impairment, or combination of impairments must be severe enough that the claimant is unable to do substantial gainful work in his/her previous occupation and—considering vocational factors such as his/her age, education, and work experience-in any other occupation within the United States economy (SEC. 223, 42 U.S.C. 423(d)(2)(A)).

The SSA disability determination process involves verifying the existence of a severe medically determinable impairment and assessing physical and mental capabilities (e.g., the ability to carry out detailed instructions). Assessing whether a claimant with a severe impairment can work in an occupation is a complex yet essential task of the SSA disability programs when determining eligibility and providing employment support services. It involves comparing the person's functional capabilities to the occupation's functional requirements. In SSA's five-step disability determination process, if a claim reaches Step 4, the adjudicator assesses the claimant's residual 
functional capacity (RFC) and determines whether the claimant is capable of performing his/her prior relevant work. If so, the claim is denied. If not so, the claim moves to Step 5 , where the adjudicator assesses whether the claimant is capable of making vocational adjustments (in terms of tools, work processes, work settings, or the industry) to be able to do other work. This other work is not expected to be "more complex" than the past relevant work. The adjudicator's Step 5 assessment is guided by the SSA MedicalVocational Grid, which characterizes the ability to make vocational adjustments based on the following vocational factors: age, education level (including literacy), skill level of past relevant work, and post-impairment physical exertional capacity (SSA 1979).

SSA is currently engaging in several initiatives to improve the disability determination process. With regard to the functional requirements of work, the forthcoming SSA OIS will contain comprehensive information on the functional requirements of occupations. It will replace the Dictionary of Occupational Titles (DOT) and be populated with information from the Occupational Requirements Survey (ORS), Occupational Information Network ( $\left.\mathrm{O}^{*} \mathrm{NET}\right)$, and several other federal occupational data systems (SSA 2018). The ORS was created and will be maintained for use in the SSA disability adjudication process. It is a survey of employers and collects information on minimum occupational requirements with respect to physical demands, mental/cognitive demands, vocational preparation needed, and environmental conditions (www.bls.gov/ors/).

With regard to vocational adjustments, in the recent past, SSA posted a funding opportunity to investigate issues related to the validity of the Medical-Vocational Grid, such as the relevance of age in the current U.S. economy, the pace at which skills from 
past work experience degrade, the pace at which educational experience degrades, and the nature of unskilled occupations.

With regard to functional capabilities, SSA funded the development of the Work Disability-Functional Assessment Battery (WD-FAB), which assess functional capability, generating eight scores with respect to four physical domains (basic mobility, upper body function, fine motor function, and community mobility) and four mental domains (cognition/communication, self-regulation, resilience/sociability, and mood/emotion) (McDonough et al. 2017, Marfeo et al. 2018). The WD-FAB has the potential to provide assessment data to supplement the information collected in the Physical and Mental Residual Functional Capacity Assessment forms used in adjudication Steps 4 and 5.

SSA also funded a 2019 National Academies study, the results of which were recently published in the "Functional Assessment for Adults with Disabilities — Consensus Study Report," which examined ways clinicians collect information about a person's work-relevant physical and mental (cognitive and noncognitive) functional abilities.

The role of functional capabilities and occupational requirements is the subject of empirical studies focusing on DI claims decisions (Lahiri, Vaughan, and Wixon 1995; Hu et al. 2001; and Lahiri, Song, and Wixon 2008). More recently, using Health and Retirement Survey (HRS) data matched to SSA records, Schimmel Hyde et al. (2018) tabulated the preapplication occupational requirements of denied claimants by reason for denial, as well as the preapplication health/functional status of denied claimants by reason for denial. Using program-based data, Strand and Trenkamp (2015) investigated the relationship between impairment and functional capabilities when 
looking at the impairments of claimants denied in Step 5 (i.e., people with impairments but sufficient functional capacity to be able to work).

However, there are few population-based estimates of the requirements of occupations held by current workers with health conditions and/or functional limitations. The analysis below seeks to begin to fill this gap and understand the need for onset information.

\section{Data, key variables, and empirical approach}

\section{Data sources}

The 2014 SIPP is a nationally representative household panel survey and a comprehensive source of employment, income, assets, program participation, health insurance, family relation, education, childcare, and food security data. The 2014 SIPP SSA Supplement contains a comprehensive source of health condition and functional limitations data, very similar to the Functional Limitations and Disability topical modules of prior SIPP panels. The SIPP core survey was conducted using in-person interviews. The SSA supplement was conducted using follow-up telephone interviews unlike the previous topical modules, which were conducted using in-person interviews.

The ORS is a new, national survey of employers and a comprehensive source of occupational requirements data, including physical, mental and cognitive demands; environmental conditions, and vocational preparation, e.g., education, experience, and training requirements (Dangermond 2015). Survey responses are used to generate 
occupation-level estimates, which are publicly available. Because ORS data collection is not yet complete for 2019, estimates from the 2017 and 2018 ORS are used here. ${ }^{1}$

We merge ORS occupation-level estimates into SIPP individual-level data via a crosswalk of the 419 ORS occupation codes and the 475 SIPP occupation codes. This crosswalk was created using crosswalks of (a) the ORS occupation code and the Standard Occupational Classification (SOC) code and (b) the SIPP occupation code and the SOC code.

Key variables

Health conditions are characterized using a series of SIPP questions. In total, a respondent has six instances in which to report a health condition, three instances via two lines of inquiry. It is feasible for a respondent to report up to six different health conditions.

In the first line of inquiry, a respondent is asked a set of functional limitation questions and a self-reported health question. If the respondent reports one or more of these functional limitations or fair/poor health, then the respondent is asked to identify the health condition that caused the functional limitation(s) or fair/poor health. Thirty-six possible health conditions are coded, such as brain injury/damage, cerebral palsy, diabetes, epilepsy, intellectual disability, and learning disability. The respondent may report up to three health conditions. If more than one health condition is reported, the respondent is asked to identify the "main" condition. Onset information is only collected for the main condition. The age of onset is defined as the age at which the main health

\footnotetext{
${ }^{1}$ A file for the 2016 ORS is available; however, to date, variable labels were not found.
} 
condition "began to bother" the person. In the analysis below, early onset occurs when the age of onset is before age 17 , which may include "since birth."

In the second line of inquiry, a respondent is asked a series of questions related to work limitation. If the respondent reports a work limitation, then the respondent is asked to identify the health condition(s) that caused the reported work limitation. The same 36 possible health conditions are used. The respondent may report up to three health conditions. If more than one health condition is reported, the respondent is asked to identify the "main" health condition. Onset information is only collected in relation to the main health condition. Furthermore, onset is based on when the health condition first started to limit work not the onset of the main health condition itself.

In the analysis below, two approaches are used to define health conditions: (1) whether a health condition was reported as the "main" health condition underlying a functional limitation(s) or fair/poor health, hereafter called the "main" approach; and (2) whether a health condition was ever reported in the six possible instances, hereafter called the "any report" approach.

It is important to note that using the report of functional limitations, fair/poor health, and work limitation to subsequently screen for a health condition is problematic. Workers with a given health condition who do not report functional limitation(s), fair/poor health, or work limitation are not included in that health condition's sample. Mitigating factors, such as medical rehabilitation therapy and workplace accommodations, may reduce the degree to which a health condition limits work ability. If the excluded workers are more likely to be in occupations with more demanding occupational requirements-relative to persons with the health condition who report functional 
limitation(s), fair/poor health, or work limitation—-then the estimates below will understate the abilities of workers with the health condition to meet these occupational requirements. Unfortunately, there is no way to overcome this issue with the SIPP data, with the exception of a few health conditions. ${ }^{2}$

Functional limitations are identified by the responses to yes/no questions related to sensory/communication functions (e.g., difficulty hearing), physical functions (e.g. , difficulty lifting/carrying 10 pounds), activities of daily living (ADLs), instrumental activities of daily living (IADLs), and behavior-related functions (e.g., trouble getting along with others). Affirmative responses to several of these questions are followed by questions that ask if the function can be perform "at all." Affirmative responses to ADL and IADL questions are followed by questions asking if help is needed. These questions are used to characterize severity. Unfortunately, onset information is not available for functional limitations.

Employment is defined by whether the main job is a job for pay (including selfemployment). The main job's occupation is defined using 475 possible occupations.

Occupational requirements are not characterized in a yes/no manner (as in $\mathrm{O}^{*} \mathrm{NET}$ ); rather, they are characterized in two basic ways. For binary requirements measures, such as whether verbal communication is required, the ORS provides the

\footnotetext{
${ }^{2}$ There are also several health condition-related questions not conditional upon reporting a functional limitation, fair/poor health, or work limitation. These health conditions are Alzheimer's disease, intellectual disability, developmental disability, learning disability, other mental or emotional conditions, and being frequently depressed or anxious. Onset information in not available for these health conditions. These health conditions are not included in the analysis below.
} 
percentage of workers within an occupation for which the requirement is required. ${ }^{3}$ For continuous variables, such as the maximum pounds required to lifted/carried, the ORS provides the average amount required of workers within an occupation. ${ }^{4}$ The ORS provides a comprehensive set of requirements, but data collection is not yet complete for all requirements and occupations. As a result, the analysis below focuses on requirements that align with the SIPP functional limitations and health conditions. These are available for nearly all occupations.

\section{Sample and sample size considerations}

The analytical sample is restricted to adults ages 18 to 72 . Age 72 is used as the upper bound to increase the number of employed persons with health conditions (i.e., increase the amount of occupational information available workers with health conditions).

The initial analysis plan for the present study included cross-tabulations by health conditions, functional limitations, occupational requirements, and vocational factors, among persons with early onset health conditions. However, the sample sizes were insufficient for such an analysis, resulting in many empty cells. For instance, imposing late onset as a sample exclusion criterion is highly restrictive. Table 1 contains sample sizes by main health condition, age of onset, and employment status. There are 7,453 persons who report a main health condition and, of these, 303 observations report early

\footnotetext{
${ }^{3}$ The ORS may also provide the percentages of workers within an occupation for which the requirement is required infrequently, required occasionally, required frequently, and required constantly. Other subcategorizations are provided for some requirements with different dimensions than time, such as whether required exposure to hazards is mitigated.

${ }^{4}$ The ORS may also provide the 10th, 25th, 50th, 75th, and 90th percentile.
} 
onset and being employed, which limits the availability of occupational information. As a result, the analysis below focuses on health conditions with larger samples: (1) back/spine problems, including chronic stiffness and deformity; (2) stiffness or deformity of the leg, foot, arm, or hand; and (3) mental or emotional problem or disorder. The occupational requirements that align well with these health conditions and have data for majority of occupations are as follows: for back/spine problems, $(A)$ the average "maximum pounds required to lifted/carried" within an occupation, (B) the percentage of workers within an occupation for which "climbing ramps or stairs is required for work" (not simply because of the work structure); for stiffness or deformity of the leg, foot, arm, or hand, $(\mathrm{C})$ the percentage of workers within an occupation for which "reaching overhead is required," (D) the percentage of workers within an occupation for which "pushing/pulling with feet/legs is required;" for mental or emotional problem or disorder, (E) the percentage of workers within an occupation for which "the pace of work has faster/slower periods," and (F) the percentage of workers within an occupation for which the "work schedule changes."

Given the restrictiveness of using early onset data, the analysis below includes the "any report" approach. Table 2 compares the sample sizes of the two approaches by employment status. Using the "main" approach yields a sample of 2,616 workers with health conditions, while using "any report" approach yields a sample of 2,804 workers with health conditions and a count of 4,185 reported health conditions by these workers. The "any report" approach yields substantially more information with which to investigate the connection between health conditions and occupational requirements, yet there is the concern of reverse causality, which will be investigated. 


\section{Empirical approach}

The analysis below is descriptive in nature. Difference-in-means tests are conducted to compare the mean of a requirement measure for those with a health condition to the mean of a requirement measure of those without that health condition. The same approach is used when comparing persons with and without a functional limitation.

To adjust for the representative nature of the SIPP sampling design, all estimates are adjusted using the SSA supplement sample weight. Standard errors and p-statistics are estimated using replicate weights and Fay's modified balanced repeated replication (BRR) method with a perturbation factor of 0.5. (U.S. Census 2015).

\section{Results}

The one-tailed difference-in-means tests in Table 3 compare the occupational requirements by health condition status (i.e., with versus without a health condition) using the "any report" approach to define a health condition's presence. Only one comparison is statistically significant.

- (Row D) The mean "within-occupation percentage of workers for which pushing/pulling with feet/legs is required" is 25 percentage points for workers with "stiffness or deformity of leg, foot, arm, or hand," which is 2.5 percentage points more than for workers without "stiffness or deformity of leg, foot, arm, or hand."

This result is inconsistent with the expectations that workers with a health condition would be less likely to be employed in occupations for which a relevant function is required. This result is consistent with concerns that a health condition arises due to an occupational requirement. 
Table 4 contains the same comparisons as Table 3, using the "main" approach to define the presences of a health condition. The statistically significant comparison in Table 3 is also statistically significant when using the "any report" approach and remains inconsistent with expectations.

- (Row D) The mean "within-occupation percent of workers for which pushing/pulling with feet/legs is required" is 25.3 percentage points for workers with "stiffness or deformity of leg, foot, arm, or hand," which is 2.8 percentage points more than for workers without "stiffness or deformity of leg, foot, arm, or hand."

And, despite smaller sample sizes, three additional comparisons are statistically significant, which may reflect the narrowing of samples to workers with more severe conditions. These three comparisons are consistent with the expectations that workers with a health condition would be less likely to be employed in occupations for which a relevant function is required.

- (Row A) The mean "within-occupation average maximum pounds required to lifted or carried" is 25.9 pounds for workers with "back or spine problems," which is 1.3 pounds less than for workers without "back or spine problems."

- (Row B) The mean "within-occupation percent of workers for which climbing ramps or stairs, work-related is required" is 20 percentage points for workers with "back or spine problems," which is 1.5 percentage points less than for workers without "back or spine problems."

- (Row F) The mean "within-occupation percent of workers for which the work schedule changes" is 45.6 percentage points for workers with "mental or emotional problem or disorder," which is 3.4 percentage points less than for workers without "mental or emotional problem or disorder." 
Table 5 contains comparisons by onset status (early onset versus late onset), using, by necessity due to survey skip patterns, the "main" approach to define the presences of a health condition. Two comparisons are statistically significant.

- (Row A) The mean "within-occupation average maximum pounds required to lifted or carried" is 20.9 pounds for workers with early onset "back or spine problems," which is 5.6 pounds less than for workers with late onset "back or spine problems."

- (Row E) The mean "within-occupation percent of workers for which the pace of work has faster/slower work periods" is 64.9 percentage points for workers with early onset "mental or emotional problem or disorder," which is 8.8 percentage points less than for workers with late onset "mental or emotional problem or disorder."

Both comparisons support concerns that the health conditions workers experience later in life may be caused by occupational requirements. For some respondents, lifting more weight at work may cause "back or spine problems." The pace of work may cause or heighten awareness of "mental or emotional problem or disorder."

Table 6 repeats the exercise of Table 3, using functional limitations rather than health conditions. ${ }^{5}$ Several comparisons are statistically significant.

- (Row A1) The mean "within-occupation average maximum pounds required to lifted or carried" is 25.2 pounds for workers with "stiffness or deformity of leg, foot, arm, or hand," which is 2.1 pounds less than for workers without "difficulty lifting or carrying 25 pounds."

\footnotetext{
${ }^{5}$ It would be interesting to limit the sample to persons with health conditions, since SSDI and SSI eligibility is conditional upon having a long lasting "medically determinable impairment," and not solely on the presence of a functional limitations. However, this is not possible given the skip patterns in the SIPP SSA Supplement.
} 
- (Row A2) The mean "within-occupation average maximum pounds required to lifted or carried" is 24.7 pounds for workers with "cannot lift or carry 25 pounds at all," which is 2.6 pounds less than for workers without "cannot lift or carry 25 pounds at all."

- (Row B1) The mean "within-occupation percent of workers for which climbing ramps or stairs, work-related is required" is 19.4 percentage points for workers with "difficulty climbing 10 stairs," which is 2.2 percentage points less than for workers without "difficulty climbing 10 stairs."

- (Row B2) The mean "within-occupation percent of workers for which climbing ramps or stairs, work-related is required" is 19.4 percentage points for workers with "cannot climb 10 stairs at all," which is 2.2 percentage points less than for workers without "cannot climb 10 stairs at all."

Two comparisons are inconsistent with expectations and may reflect the simultaneity of functional limitations and occupational requirements.

- (Row C) The mean "within-occupation percent of workers for which reaching overhead is required" is 52.1 percentage points for workers with "difficulty reaching over head," which is 2.2 percentage points more than for workers without "difficulty reaching over head."

- (Row F1) The mean "within-occupation percent of workers for which the work schedule changes" is 50.9 percentage points for workers with "difficulty concentrating enough to finish everyday tasks," which is 1.9 percentage points more than for workers without "difficulty concentrating enough to finish everyday tasks."

Both comparisons support concerns that workers' functional limitations may be caused by occupational requirements. For some respondents, being required to reach overhead at work may cause "difficulty reaching overhead." Changing work schedules may cause or heighten awareness of "difficulty concentrating." 


\section{Concluding remarks}

Population-based survey data on the requirements of occupations held by workers with health conditions and functional limitations has the potential, in several ways, to inform the SSA disability determination process, as a complement to program data and expert panels. Some of the estimates above demonstrate that claimants with certain health conditions may be able to fulfill the requirements in certain occupations. A similar approach, with more expansive data, could be used to investigate the validity of the Listing of Impairments-which contains health conditions ${ }^{6}$ for which the documented presence is sufficient to deem (assuming earnings requirements are met) a claimant eligible for benefits. This would involve looking at the employment, earnings, occupational requirements of workers with conditions in the Listings. Similarly, the validity of SSA residual functional capacity forms-which are used to assess claimant physical and mental function—could be investigated by looking at whether additional or fewer questions are needed to assess functional capacity relative to occupational requirements; e.g., an item reduction analysis. Decisions made via the MedicalVocational Grid, the decision making guide used in the fifth and last step of SSA's sequential review process to assess claimant residual functional capacity and vocational factors against relatively broad occupational requirements—could be simulated and examined to inform the development of the materials in SSA's upcoming occupational grid. ${ }^{7}$

\footnotetext{
${ }^{6}$ An example is the loss of central visual acuity with the remaining vision in the better eye after best correction is $20 / 200$ or less (SSA 2019).

${ }^{7}$ See CFR 404.1520 for details about the SSA's sequential review process.
} 
The results presented above demonstrate the ability and limitations of using survey data to the examine the connection between health conditions, functional limitations, and occupational requirements. To better inform SSA policy, the specificity of onset questions (date and cause) need to be expanded, and a sampling strategy to address low-incidence health conditions may need to be implemented. 


\section{References}

Dangermond, Nicole. "The Occupational Requirements Survey: estimates from preproduction testing." Monthly Labor Review 138, (2015): 1.

Hu, Jianting, Kajal Lahiri, Denton R. Vaughan, and Bernard Wixon. "A structural model of social security's disability determination process." Review of Economics and Statistics 83, no. 2 (2001): 348-361.

Lahiri, Kajal, Denton R. Vaughan, and Bernard Wixon. "Modeling SSA's sequential disability determination process using matched SIPP data." Social Security Bulletin 58 (1995): 3.

Lahiri, Kajal, Jae Song, and Bernard Wixon. "A model of Social Security Disability Insurance using matched SIPP/Administrative data." Journal of Econometrics 145, no. 1-2 (2008): 4-20.

Marfeo, Elizabeth, Pengsheng Ni, Christine McDonough, Kara Peterik, Molly Marino, Mark Meterko, Elizabeth Rasch, Leighton Chan, Diane Brandt, and Alan Jette. "Improving Assessment of Work Related Mental Health Function Using the Work Disability Functional Assessment Battery (WD-FAB)." Journal of Occupational Rehabilitation 28.1 (2018): 190-199.

McDonough, Christine, Pengsheng Ni, Kara Peterik, Elizabeth Marfeo Molly Marino, Mark Meterko. Elizabeth Rasch, Diane Brandt, Alan Jette, and Leighton Chan. "Improving Measures of Work-Related Physical Functioning." Quality of Life Research 26.3 (2017): 789-798.

National Academies of Sciences, Engineering, and Medicine. Functional Assessment for Adults with Disabilities. National Academies Press, 2019.

Rasch, Elizabeth K., et al. "First in line: Prioritizing receipt of Social Security disability benefits based on likelihood of death during adjudication." Medical care 52.11 (2014): 944. 
Social Security Administration. Occupational Information System Project. www.ssa.gov/disabilityresearch/occupational_info_systems.html. Accessed 4 April 2018.

Social Security Administration. Listing of Impairments - Adult Listings (Part A). https://www.ssa.gov/disability/professionals/bluebook/AdultListings.htm. Accessed 18 September 2019.

Social Security Administration. SSR 82-41: Titles II and XVI: Work Skills and their Transferability as Intended by the Expanded Vocational Factors Regulations Effective February 26, 1979.

Schimmel Hyde, Jody, April Wu, and Lakhpreet Gill. "The Benefit Receipt Patterns and Labor Market Experiences of Older Workers Who Were Denied SSDI on the Basis of Work Capacity." DRC Working Paper, March 2018, No. 2018-01. Mathematica Policy Research.

Strand, Alexander, and Brad Trenkamp. "When Impairments Cause a Change in Occupation." Social Security Bulletin 75 (2015): 1.

U.S. Census Bureau. Survey of Income and Program Participation, 2014 Panel Users' Guide, First Edition. (2015). Washington, D.C.: U.S. Department of Commerce, Economics and Statistics Administration. 
Table 1. Sample size by main health condition (causing functional limitations or fair/poor health under), age of onset, and employment status, persons ages 18 to 72

\begin{tabular}{|c|c|c|c|c|c|}
\hline \multirow[b]{2}{*}{ Health condition } & \multirow[b]{2}{*}{ Total } & \multicolumn{2}{|c|}{ Early onset } & \multicolumn{2}{|c|}{ Late onset } \\
\hline & & Employed & $\begin{array}{c}\text { Not } \\
\text { employed }\end{array}$ & Employed & $\begin{array}{c}\text { Not } \\
\text { employed }\end{array}$ \\
\hline Total (number of persons) & 7,453 & 303 & 498 & 2,313 & 4,339 \\
\hline - Alcohol or drug problem or disorder & 6 & 0 & 1 & 1 & 4 \\
\hline - AIDS or AIDS Related Condition (ARC) & 9 & 0 & 1 & 0 & 8 \\
\hline - Arthritis or rheumatism & 1,102 & 15 & 23 & 374 & 690 \\
\hline $\begin{array}{l}\text { - Back or spine problems, incl. chronic } \\
\text { stiffness \& deformity }\end{array}$ & 1,113 & 33 & 43 & 343 & 694 \\
\hline - Blindness or vision problems & 135 & 18 & 27 & 22 & 68 \\
\hline - Broken bone/fracture & 176 & 6 & 4 & 58 & 108 \\
\hline - Cancer & 113 & 1 & 5 & 20 & 87 \\
\hline - Cerebral palsy & 22 & 7 & 12 & 0 & 3 \\
\hline - Diabetes & 234 & 3 & 8 & 65 & 158 \\
\hline - Epilepsy & 34 & 1 & 13 & 3 & 17 \\
\hline - Heart trouble & 246 & 4 & 9 & 43 & 190 \\
\hline - Hernia or rupture & 33 & 0 & 0 & 15 & 18 \\
\hline - High blood pressure & 50 & 0 & 1 & 15 & 34 \\
\hline - Kidney problems & 49 & 1 & 1 & 5 & 42 \\
\hline - Learning disability & 43 & 13 & 17 & 4 & 9 \\
\hline - Lung or respiratory problems & 312 & 10 & 19 & 54 & 229 \\
\hline $\begin{array}{l}\text { - Mental or emotional problem or } \\
\text { disorder }\end{array}$ & 269 & 16 & 57 & 47 & 149 \\
\hline $\begin{array}{l}\text { - Intellectual disability, formerly mental } \\
\text { retardation }\end{array}$ & 109 & 14 & 59 & 5 & 31 \\
\hline $\begin{array}{l}\text { - Missing legs, feet, arms, hands, or } \\
\text { fingers }\end{array}$ & 11 & 0 & 1 & 3 & 7 \\
\hline - Senility/Dementia/Alzheimer's disease & 49 & 0 & 2 & 3 & 44 \\
\hline $\begin{array}{l}\text { - Stiffness or deformity of the leg, foot, } \\
\text { arm, or hand }\end{array}$ & 625 & 26 & 21 & 287 & 291 \\
\hline $\begin{array}{l}\text { - Stomach trouble, incl. ulcers, } \\
\text { gallbladder, or liver conditions }\end{array}$ & 29 & 1 & 1 & 9 & 18 \\
\hline - Stroke & 135 & 0 & 4 & 13 & 118 \\
\hline - Thyroid trouble or goiter & 9 & 0 & 0 & 4 & 5 \\
\hline - Tumor, cyst, or growth & 30 & 0 & 0 & 19 & 11 \\
\hline - Other & 1,872 & 100 & 105 & 727 & 940 \\
\hline $\begin{array}{l}\text { - Autistic or other developmental } \\
\text { disorders }\end{array}$ & 42 & 10 & 22 & 3 & 7 \\
\hline - Autoimmune disorders & 27 & 1 & 0 & 10 & 16 \\
\hline - Brain injury/damage & 31 & 2 & 3 & 2 & 24 \\
\hline $\begin{array}{l}\text { - Conditions or diseases affecting the } \\
\text { veins/arteries }\end{array}$ & 21 & 1 & 1 & 5 & 14 \\
\hline - Hematological disorders & 57 & 1 & 7 & 22 & 27 \\
\hline $\begin{array}{l}\text { - Other neurological disorders or } \\
\text { conditions }\end{array}$ & 304 & 14 & 22 & 75 & 193 \\
\hline $\begin{array}{l}\text { - Other digestive system disorders or } \\
\text { conditions }\end{array}$ & 23 & 0 & 2 & 5 & 16 \\
\hline - Other endocrine system disorders & 2 & 0 & 0 & 0 & 2 \\
\hline - Other genetic or congenital conditions & 14 & 5 & 4 & 1 & 4 \\
\hline - Pain disorders & 117 & 0 & 3 & 51 & 63 \\
\hline
\end{tabular}

Source: 2014 Survey of Income and Program Participation, Social Security Supplement. 
Table 2. Sample size by approach to coding health condition, by employment status, persons ages 18 to 72

\begin{tabular}{|c|c|c|c|c|c|c|}
\hline \multirow{2}{*}{ Health condition } & \multicolumn{3}{|c|}{ Main health condition } & \multicolumn{3}{|c|}{$\begin{array}{l}\text { Any report of health } \\
\text { condition }\end{array}$} \\
\hline & Total & Employed & \begin{tabular}{|c|}
$\begin{array}{c}\text { Not } \\
\text { employed }\end{array}$ \\
\end{tabular} & Total & Employed & $\begin{array}{c}\begin{array}{c}\text { Not } \\
\text { employed }\end{array} \\
\end{array}$ \\
\hline Total, duplicated (i.e., count of conditions) & 7,453 & 2,616 & 4,837 & 14,979 & 4,185 & 10,794 \\
\hline Total, unduplicated (i.e., number of persons) & 7,453 & 2,616 & 4,837 & 7,961 & 2,804 & 5,157 \\
\hline - Alcohol or drug problem or disorder & 6 & 1 & 5 & 21 & 5 & 16 \\
\hline - AIDS or AIDS Related Condition (ARC) & 9 & 0 & 9 & 20 & 0 & 20 \\
\hline - Arthritis or rheumatism & 1,102 & 389 & 713 & 1,918 & 563 & 1,355 \\
\hline $\begin{array}{l}\text { - Back or spine problems, incl. chronic stiffness \& } \\
\text { deformity }\end{array}$ & 1,113 & 376 & 737 & 1,779 & 517 & 1,262 \\
\hline - Blindness or vision problems & 135 & 40 & 95 & 268 & 70 & 198 \\
\hline - Broken bone/fracture & 176 & 64 & 112 & 396 & 116 & 280 \\
\hline - Cancer & 113 & 21 & 92 & 302 & 63 & 239 \\
\hline - Cerebral palsy & 22 & 7 & 15 & 43 & 12 & 31 \\
\hline - Diabetes & 234 & 68 & 166 & 814 & 176 & 638 \\
\hline - Epilepsy & 34 & 4 & 30 & 118 & 19 & 99 \\
\hline - Heart trouble & 246 & 47 & 199 & 660 & 115 & 545 \\
\hline - Hernia or rupture & 33 & 15 & 18 & 79 & 28 & 51 \\
\hline - High blood pressure & 50 & 15 & 35 & 501 & 103 & 398 \\
\hline - Kidney problems & 49 & 6 & 43 & 155 & 27 & 128 \\
\hline - Learning disability & 43 & 17 & 26 & 129 & 43 & 86 \\
\hline - Lung or respiratory problems & 312 & 64 & 248 & 709 & 148 & 561 \\
\hline - Mental or emotional problem or disorder & 269 & 63 & 206 & 807 & 141 & 666 \\
\hline - Intellectual disability, formerly mental retardation & 109 & 19 & 90 & 198 & 35 & 163 \\
\hline - Missing legs, feet, arms, hands, or fingers & 11 & 3 & 8 & 21 & 6 & 15 \\
\hline - Senility/Dementia/Alzheimer's disease & 49 & 3 & 46 & 134 & 12 & 122 \\
\hline $\begin{array}{l}\text { - Stiffness or deformity of the leg, foot, arm, or } \\
\text { hand }\end{array}$ & 625 & 313 & 312 & 1,075 & 426 & 649 \\
\hline $\begin{array}{l}\text { - Stomach trouble, incl. ulcers, gallbladder, or } \\
\text { liver conditions }\end{array}$ & 29 & 10 & 19 & 113 & 25 & 88 \\
\hline - Stroke & 135 & 13 & 122 & 236 & 25 & 211 \\
\hline - Thyroid trouble or goiter & 9 & 4 & 5 & 55 & 19 & 36 \\
\hline - Tumor, cyst, or growth & 30 & 19 & 11 & 75 & 28 & 47 \\
\hline - Other & 1,872 & 827 & 1,045 & 3,072 & 1,125 & 1,947 \\
\hline - Autistic or other developmental disorders & 42 & 13 & 29 & 63 & 21 & 42 \\
\hline - Autoimmune disorders & 27 & 11 & 16 & 73 & 20 & 53 \\
\hline - Brain injury/damage & 31 & 4 & 27 & 46 & 5 & 41 \\
\hline $\begin{array}{l}\text { - Conditions or diseases affecting the } \\
\text { veins/arteries }\end{array}$ & 21 & 6 & 15 & 44 & 8 & 36 \\
\hline - Hematological disorders & 57 & 23 & 34 & 150 & 40 & 110 \\
\hline - Other neurological disorders or conditions & 304 & 89 & 215 & 552 & 137 & 415 \\
\hline - Other digestive system disorders or conditions & 23 & 5 & 18 & 105 & 24 & 81 \\
\hline - Other endocrine system disorders & 2 & 0 & 2 & 9 & 0 & 9 \\
\hline - Other genetic or congenital conditions & 14 & 6 & 8 & 25 & 10 & 15 \\
\hline - Pain disorders & 117 & 51 & 66 & 214 & 73 & 141 \\
\hline
\end{tabular}

Source: 2014 Survey of Income and Program Participation, Social Security Supplement. 
Table 3. Means of requirement measures among workers ages 18 to 72 by health condition, health condition status, using the "any report" approach to define health conditions

\begin{tabular}{|c|c|c|c|c|c|c|c|c|c|c|}
\hline \multirow{3}{*}{ Health condition } & \multirow{3}{*}{ Requirement measure } & \multicolumn{6}{|c|}{$\begin{array}{l}\text { Health condition status (Any report of health } \\
\text { condition) }\end{array}$} & \multirow{2}{*}{\multicolumn{2}{|c|}{$\begin{array}{l}\text { Difference-in- } \\
\text { mean test }\end{array}$}} & \multirow[t]{3}{*}{ Row } \\
\hline & & & With & & & Vithout & & & & \\
\hline & & Obs. & Mean & S.E. & Obs. & Mean & S.E. & Dif. & p-Stat. & \\
\hline \multirow{4}{*}{$\begin{array}{l}\text { Back or spine problems, } \\
\text { including chronic } \\
\text { stiffness and deformity }\end{array}$} & Average (within occupation): & & & & & & & & & \\
\hline & $\begin{array}{l}\text { - Maximum pounds required to } \\
\text { lifted/carried }\end{array}$ & 477 & 26.2 & 0.84 & 12,528 & 27.2 & 0.20 & -1.0 & 0.11 & A \\
\hline & $\begin{array}{l}\text { Percentage of workers (within occ.) for } \\
\text { which: }\end{array}$ & & & & & & & & & \\
\hline & $\begin{array}{l}\text { - Climbing ramps or stairs, work- } \\
\text { related is required }\end{array}$ & 487 & 20.5 & 0.95 & 12,887 & 21.5 & 0.19 & -1.0 & 0.15 & B \\
\hline \multirow{3}{*}{$\begin{array}{l}\text { Stiffness or deformity of } \\
\text { leg, foot, arm, or hand, } \\
\text { including joints }\end{array}$} & $\begin{array}{l}\text { Percentage of workers (within occ.) for } \\
\text { which: }\end{array}$ & & & & & & & & & \\
\hline & - Reaching overhead is required & 394 & 51.1 & 1.37 & 12,783 & 50.0 & 0.26 & 1.1 & 0.21 & C \\
\hline & $\begin{array}{l}\text { - Pushing/pulling with feet/legs is } \\
\text { required }\end{array}$ & 399 & 25.0 & 1.37 & 12,931 & 22.5 & 0.24 & 2.5 & $0.04^{* *}$ & D \\
\hline \multirow[t]{3}{*}{$\begin{array}{l}\text { Mental or emotional } \\
\text { problem or disorder }\end{array}$} & $\begin{array}{l}\text { Percentage of workers (within occ.) for } \\
\text { which the: }\end{array}$ & & & & & & & & & \\
\hline & $\begin{array}{l}\text { - Pace of work has faster/slower } \\
\text { periods }\end{array}$ & 78 & 72.6 & 1.57 & 7,017 & 73.9 & 0.16 & -1.3 & 0.20 & E \\
\hline & - Work schedule changes & 96 & 48.9 & 1.82 & 9,387 & 49.0 & 0.17 & -0.1 & 0.48 & $\mathrm{~F}$ \\
\hline
\end{tabular}

Source: 2014 Survey of Income and Program Participation, Social Security Supplement and 2017 and 2018 Occupational Requirements Survey. Note: All estimates are adjusted using sample weights and replicate weights. The p-statistic is for one-tailed test. Statistically significance is indicated with ${ }^{* * *},{ }^{* *},{ }^{*}$ at the $0.01,0.05$, and 0.1 levels of significance, respectively. 
Table 4. Means of requirement measures among workers ages 18 to 72 by health condition, health condition status, using the "main" approach to define health conditions

\begin{tabular}{|c|c|c|c|c|c|c|c|c|c|c|}
\hline \multirow{3}{*}{ Health condition } & \multirow{3}{*}{ Requirement measure } & \multicolumn{6}{|c|}{$\begin{array}{l}\text { Health condition status } \\
\text { (Main health condition) }\end{array}$} & \multirow{2}{*}{\multicolumn{2}{|c|}{$\begin{array}{l}\text { Difference-in- } \\
\text { mean test }\end{array}$}} & \multirow{3}{*}{$\begin{array}{l}\text { Ro } \\
\text { w }\end{array}$} \\
\hline & & \multicolumn{3}{|c|}{ With } & \multicolumn{3}{|c|}{ Without } & & & \\
\hline & & Obs. & Mean & S.E. & Obs. & Mean & S.E. & Dif. & p-Stat. & \\
\hline \multirow{4}{*}{$\begin{array}{l}\text { Back or spine problems, } \\
\text { including chronic stiffness } \\
\text { and deformity }\end{array}$} & Average (within occupation): & & & & & & & & & \\
\hline & $\begin{array}{l}\text { - Maximum pounds } \\
\text { required to lifted/carried }\end{array}$ & 347 & 25.9 & 0.97 & 12,658 & 27.2 & 0.19 & -1.3 & $0.08^{*}$ & A \\
\hline & $\begin{array}{l}\text { Percentage of workers } \\
\text { (within occ.) for which: }\end{array}$ & & & & & & & & & \\
\hline & $\begin{array}{l}\text { - Climbing ramps or stairs, } \\
\text { work-related is required }\end{array}$ & 355 & 20.0 & 1.14 & 13,019 & 21.5 & 0.19 & -1.5 & $0.10 *$ & $\mathrm{~B}$ \\
\hline \multirow{3}{*}{$\begin{array}{l}\text { Stiffness or deformity of leg, } \\
\text { foot, arm, or hand, including } \\
\text { joints }\end{array}$} & $\begin{array}{l}\text { Percentage of workers } \\
\text { (within occ.) for which: }\end{array}$ & & & & & & & & & \\
\hline & $\begin{array}{l}\text { - Reaching overhead is } \\
\text { required }\end{array}$ & 289 & 52.0 & 1.63 & 12,888 & 50.0 & 0.26 & 2.0 & 0.11 & C \\
\hline & $\begin{array}{l}\text { - Pushing/pulling with } \\
\text { feet/legs is required }\end{array}$ & 295 & 25.3 & 1.60 & 13,035 & 22.5 & 0.24 & 2.8 & $0.04^{* *}$ & $\mathrm{D}$ \\
\hline \multirow[t]{3}{*}{$\begin{array}{l}\text { Mental or emotional problem } \\
\text { or disorder }\end{array}$} & $\begin{array}{l}\text { Percentage of workers } \\
\text { (within occ.) for which the: }\end{array}$ & & & & & & & & & \\
\hline & $\begin{array}{l}\text { - Pace of work has } \\
\text { faster/slower periods }\end{array}$ & 29 & 71.0 & 2.53 & 7,066 & 73.9 & 0.16 & -2.9 & 0.12 & $E$ \\
\hline & - Work schedule changes & 41 & 45.6 & 2.37 & 9,442 & 49.0 & 0.18 & -3.4 & $0.08^{*}$ & $\mathrm{~F}$ \\
\hline
\end{tabular}

Source: 2014 Survey of Income and Program Participation, Social Security Supplement and 2017 and 2018 Occupational Requirements Survey. Note: All estimates are adjusted using sample weights and replicate weights. The p-statistic is for one-tailed test. Statistically significance is indicated with ${ }^{* * *},{ }^{* *},{ }^{*}$ at the $0.01,0.05$, and 0.1 levels of significance, respectively. 
Table 5. Means of requirement measures among workers ages 18 to 72 with health conditions, by health condition and early onset status, using the "main" approach to define health conditions and comparing by onset status

\begin{tabular}{|c|c|c|c|c|c|c|c|c|c|c|}
\hline \multirow{3}{*}{ Health condition } & \multirow{3}{*}{ Requirement measure } & \multicolumn{6}{|c|}{ Onset status } & \multirow{2}{*}{\multicolumn{2}{|c|}{\begin{tabular}{|c|} 
Difference \\
-in-mean \\
test
\end{tabular}}} & \multirow{3}{*}{ Row } \\
\hline & & \multicolumn{3}{|c|}{$\begin{array}{c}\text { Early (ages } 16 \text { or } \\
\text { under) }\end{array}$} & \multicolumn{3}{|c|}{$\begin{array}{c}\text { Late (ages } 17 \text { or } \\
\text { over) }\end{array}$} & & & \\
\hline & & Obs. & Mean & S.E. & Obs. & Mean & S.E. & Dif. & $\begin{array}{c}\text { p- } \\
\text { Stat }\end{array}$ & \\
\hline \multirow{4}{*}{$\begin{array}{l}\text { Back or spine problems, } \\
\text { including chronic } \\
\text { stiffness and deformity }\end{array}$} & Average (within occupation): & & & & & & & & & \\
\hline & $\begin{array}{l}\text { - Maximum pounds required to } \\
\text { lifted/carried }\end{array}$ & 33 & 20.9 & 2.88 & 314 & 26.5 & 0.98 & -5.6 & $\begin{array}{c}0.03 \\
* *\end{array}$ & A \\
\hline & $\begin{array}{l}\text { Percentage of workers (within } \\
\text { occ.) for which: }\end{array}$ & & & & & & & & & \\
\hline & \begin{tabular}{|l|} 
- Climbing ramps or stairs, \\
work-related is required
\end{tabular} & 33 & 16.5 & 3.57 & 322 & 20.5 & 1.18 & -4.0 & 0.14 & B \\
\hline \multirow{3}{*}{$\begin{array}{l}\text { Stiffness or deformity of } \\
\text { leg, foot, arm, or hand, } \\
\text { including joints }\end{array}$} & $\begin{array}{l}\text { Percentage of workers (within } \\
\text { occ.) for which: }\end{array}$ & & & & & & & & & \\
\hline & $\begin{array}{l}\text { - Reaching overhead is } \\
\text { required }\end{array}$ & 25 & 56.9 & 6.75 & 264 & 51.5 & 1.64 & 5.4 & 0.21 & C \\
\hline & $\begin{array}{l}\text { - Pushing/pulling with feet/legs } \\
\text { is required }\end{array}$ & 26 & 24.7 & 5.34 & 269 & 25.4 & 1.68 & -0.7 & 0.45 & D \\
\hline \multirow[t]{3}{*}{$\begin{array}{l}\text { Mental or emotional } \\
\text { problem or disorder }\end{array}$} & $\begin{array}{l}\text { Percentage of workers (within } \\
\text { occ.) for which the: }\end{array}$ & & & & & & & & & \\
\hline & $\begin{array}{l}\text { - Pace of work has } \\
\text { faster/slower periods }\end{array}$ & 8 & 64.9 & 4.49 & 21 & 73.7 & 2.57 & -8.8 & $\underset{* *}{0.04}$ & $E$ \\
\hline & - Work schedule changes & 13 & 41.7 & 4.81 & 28 & 47.4 & 2.44 & -5.7 & 0.14 & $\mathrm{~F}$ \\
\hline
\end{tabular}

Source: 2014 Survey of Income and Program Participation, Social Security Supplement and 2017 and 2018 Occupational Requirements Survey. Note: All estimates are adjusted using sample weights and replicate weights. The p-statistic is for one-tailed test. Statistically significance is indicated with ${ }^{* * *},{ }^{* *},{ }^{*}$ at the $0.01,0.05$, and 0.1 levels of significance, respectively 
Table 6. Means of requirement measures among workers ages 18 to 72 , by functional limitation status

\begin{tabular}{|c|c|c|c|c|c|c|c|c|c|c|}
\hline \multirow{3}{*}{ Functional limitation } & \multirow{3}{*}{ Requirement measure } & \multicolumn{6}{|c|}{ Functional limitation } & \multirow{2}{*}{\multicolumn{2}{|c|}{$\begin{array}{c}\text { Difference- } \\
\text { in-mean } \\
\text { test }\end{array}$}} & \multirow{3}{*}{ Row } \\
\hline & & \multicolumn{3}{|c|}{ With } & \multicolumn{3}{|c|}{ Without } & & & \\
\hline & & Obs. & Mean & S.E. & Obs. & Mean & S.E. & Dif. & $\begin{array}{c}\mathrm{p}- \\
\text { Stat. }\end{array}$ & \\
\hline & Average (within occupation): & & & & & & & & & \\
\hline $\begin{array}{l}\text { Difficulty lifting or carrying } 25 \\
\text { pounds }\end{array}$ & \multirow[t]{2}{*}{$\begin{array}{l}\text { - Maximum pounds required to } \\
\text { lifted/carried }\end{array}$} & 1,019 & 25.2 & 0.58 & 11,986 & 27.3 & 0.20 & -2.1 & $0.00^{* * *} \mid$ & A1 \\
\hline \multirow[t]{2}{*}{$\begin{array}{l}\text { - Cannot lift or carry } 25 \\
\text { pounds at all }\end{array}$} & & 519 & 24.7 & 0.73 & 12,486 & 27.3 & 0.20 & -2.6 & $0.00^{* * *}$ & A2 \\
\hline & $\begin{array}{l}\text { Percentage of workers (within } \\
\text { an occupation) for which: }\end{array}$ & & & & & & & & & \\
\hline \multirow{2}{*}{$\begin{array}{l}\text { Difficulty climbing } 10 \text { stairs } \\
\text { - Cannot climb } 10 \text { stairs at all }\end{array}$} & \multirow{2}{*}{$\begin{array}{l}\text { - Climbing ramps or stairs, } \\
\text { work-related is required }\end{array}$} & 585 & 19.4 & 0.73 & 12,789 & 21.6 & 0.18 & -2.2 & $0.00^{* * *}$ & B1 \\
\hline & & 500 & 19.4 & 0.79 & 12,874 & 21.6 & 0.18 & -2.2 & $0.00^{* * *}$ & B2 \\
\hline Difficulty reaching over head & $\begin{array}{l}\text { - Reaching overhead is } \\
\text { required }\end{array}$ & 402 & 52.1 & 1.51 & 12,775 & 49.9 & 0.26 & 2.2 & $0.08^{*}$ & C \\
\hline Difficulty pushing large object & \multirow[t]{2}{*}{$\begin{array}{l}\text { - Pushing/pulling with feet/legs } \\
\text { is required }\end{array}$} & 732 & 22.7 & 0.97 & 12,598 & 22.5 & 0.24 & 0.2 & 0.45 & D1 \\
\hline \multirow[t]{2}{*}{$\begin{array}{l}\text { - Cannot push large object at } \\
\text { all }\end{array}$} & & 370 & 21.3 & 1.39 & 12,960 & 22.6 & 0.24 & -1.3 & 0.19 & D2 \\
\hline & $\begin{array}{l}\text { Percentage of workers (within } \\
\text { an occ.) for which the: }\end{array}$ & & & & & & & & & \\
\hline $\begin{array}{l}\text { Difficulty concentrating } \\
\text { enough to finish everyday } \\
\text { tasks }\end{array}$ & \multirow[t]{2}{*}{$\begin{array}{l}\text { - Pace of work has } \\
\text { faster/slower work periods }\end{array}$} & 212 & 74.5 & 0.97 & 6,883 & 73.9 & 0.16 & 0.6 & 0.25 & E1 \\
\hline $\begin{array}{l}\text { Difficulty coping with day to } \\
\text { day stresses }\end{array}$ & & 282 & 74.0 & 0.87 & 6,813 & 73.9 & 0.16 & 0.1 & 0.46 & E2 \\
\hline $\begin{array}{l}\text { Difficulty concentrating } \\
\text { enough to finish everyday } \\
\text { tasks }\end{array}$ & \multirow[t]{2}{*}{ - Schedule changes } & 291 & 50.9 & 0.99 & 9,192 & 49.0 & 0.18 & 1.9 & $0.03^{\star *}$ & F1 \\
\hline $\begin{array}{l}\text { Difficulty coping with day to } \\
\text { day stresses }\end{array}$ & & 380 & 49.4 & 0.95 & 9,103 & 49.0 & 0.18 & 0.4 & 0.33 & F2 \\
\hline
\end{tabular}

Source: 2014 Survey of Income and Program Participation, Social Security Supplement and 2017 and 2018 Occupational Requirements Survey. Note: All estimates are adjusted using sample weights and replicate weights. The p-statistic is for one-tailed test. Statistically significance is indicated with ${ }^{* * *},{ }^{* *},{ }^{*}$ at the $0.01,0.05$, and 0.1 levels of significance, respectively. 